\title{
CrimRxiv
}

\section{Living with Warrants: Life Under the Sword of Damocles}

Janelle Duda-Banwar ${ }^{1}$, Jessica M. Burt ${ }^{1}$

${ }^{1}$ Center for Public Saf ety Initiatives, Rochester Institute of Technology

Published on: Jan 31, 2022

License: Creative Commons Attribution 4.0 International License (CC-BY 4.0). 


\begin{abstract}
Most criminal justice processing is for low-level offenses, not serious, violent offenses. Bench warrants, issued for non-compliance with court orders, disrupt lives, as arrest is imminent. The purpose of this study is to understand how and why individuals fail to resolve their warrant and their subsequent response to this status. This study utilized Strauss and Corbin's grounded theory approach to understand how individuals manage low-level fugitive status. Twenty-six in-depth interviews were conducted with individuals with current bench warrants and trusted individuals in their lives. The results reveal a core category of risk calculation and the additional categories of: strategies to evade arrest, power creation, emotional distress, surrender planning, warrant resolution, escalation, and distrust of the justice system. The results indicate that bench warrants have longstanding impacts on individuals, often pushing them to detach from society. Implications for criminal justice practice and policy include the implementation of court reminder systems and financial hardship hearings.
\end{abstract}

\title{
Introduction
}

There are millions of individuals living under the constant threat of arrest due to a bench warrant (Bierie, 2014; Sekhon, 2017). Bench warrants can stem from violations to unpaid legal financial obligations to misdemeanors to serious felony offenses, yet the consequence of a warrant is the same regardless: incarceration. Even charges or violations that originally carried no jail time can escalate into the possibility of arrest and subsequent incarceration for non-compliance with court orders. In practice, these powerful bench warrants escalate problems for individuals that intentionally or unintentionally miss court. Surprisingly, however, there has been a dearth of research on bench warrants.

At first glance, bench warrants are easy to ignore, as they are an administrative "sanction," not worthy of a second thought. These warrants are simply one more tool, used at the discretion of judges, to make court processing fast and efficient. However, the limited research indicates that these administrative warrants do significantly and adversely impact individuals' lives, frequently leading to disruption and disconnection (Flannery \& Kretschmar, 2012; Galanek, Duda-Banwar, Flannery, Butcher, Kretschmar, 2016). This study seeks to bridge the gap between research and the practical implications of living with a bench warrant. Interviews with this population will lead to the development of theory to understand how individuals manage low-level fugitive 
status. The alternative is for researchers to continue to overlook this judicial tool, perpetuating the narrative that bench warrants are inconsequential.

With a lack of theory to guide the study of bench warrants, theory development was needed. Grounded theory interviews with both individuals with warrants and trusted individuals in the lives of people with warrants were conducted to examine how individuals manage living with this warrant status. The identification of concepts and their proposed relationships provides guidance on which concepts to include in future models that study this population. These findings provide in depth descriptions, directly from the individuals themselves, of what it means to live with a warrant hanging over their head.

This threat of arrest seems to parallel the position that Damocles, a courtier, was put in by the tyrant King Dionysius II in the 4th century B.C. As told by Cicero (trans. 1877), King Dionysius offered Damocles the king's fortune, with Damocles eagerly accepting the riches. Within moments, Damocles realized the catch: suspended by a single horsehair above his head, hung a sword, ready to drop at any moment. Damocles no longer had a desire for this life and realized, "There can be no happiness for one who is under constant apprehensions." Damocles quickly understood that living under constant threat was no way to live (Cicero, trans. 1877).

\section{Background}

The majority of arrests are for low-level offenses, including misdemeanor crimes and violations. Across New York State, 66\% of the more than 400,000 adult arrests in 2018 were for misdemeanor crimes. This trend is similar, even as high as $80 \%$, across the country (Natapoff, 2016). However, as Chauhan and Travis (2018) point out, while most criminal justice efforts and subsequent court processing are for misdemeanor crimes, much less scholarly attention has been paid to this area. Even less attention has been given to bench warrants (Bierie, 2014), yet bench warrants, issued postarraignment for administrative reasons such as failure to appear or pay a fine, are the most frequent type of warrant issued (Guynes \& Wolff, 2004; Hager, 2005).

Data on warrants are scarce, with the National Crime Information Center's (NCIC) database being the best national estimate on warrant incidence data. There were 1.95 million warrants in the Wanted Persons file in the NCIC database on a particular day in 2011 (Bierie, 2014). However, the NCIC database's Wanted Persons file is comprised of individuals who have outstanding federal warrants (Federation of American Scientists, 2008), is more often used for extradition purposes (Guynes \& Wolff, 2004), and is not a 
mandatory system (Bierie, 2014); therefore, lower level warrants are not included in this database. For example, there were an estimated 265,000-385,000 unserved arrest warrants in the State of Kentucky in 2005 (Hager, 2005), yet in the NCIC Wanted Persons database, there were only 13,066 warrants listed for Kentucky. Even with a lack of systematic data collection, this data suggests that there is a high volume of warrants.

Guynes and Wolff's (2004) descriptive examination of two jurisdictions' warrant databases reveals the low-level nature of warrants. In the two counties studied, the majority of warrants were issued for failure to appear. In many jurisdictions, noncriminal offenses, such as unpaid traffic tickets, frequently escalate into criminal offenses (e.g., license suspended for failure to pay traffic violation, yet continue to drive and charged with criminal offense of unlicensed operation of a motor vehicle). These traffic violations, which carry no jail time, are the most common original offense for bench warrants (Guynes \& Wolff, 2004; Sekhon, 2017).

The social justice implications cannot be ignored. Existing evidence on bench warrants suggests that this status is pervasive, and frequently originates with minor offenses (Flannery, 2013; Guynes \& Wolff, 2004; Sekhon, 2017). Yet, is incarceration an appropriate response to a missed court appearance or failure to pay? Some practitioners have identified this status as a problem that not only creates warrant backlogs, but also unfairly impacts people's lives. Jurisdictions like Harlem, Manhattan, Detroit, Cleveland and Atlanta have all implemented either full amnesty or partial amnesty programs for individuals with bench warrants (Carleo-Evangelist, 2015; Driscoll, 2015; Flannery, 2013; Kinch, 2015; and McKinley, 2017.) The Manhattan District Attorney asserted that these outstanding warrants were driving a wedge between the police and the community and creating unnecessary obstacles for individuals related to housing and employment (McKinley, 2017).

Even federal law enforcement has been impacted by these low-level warrants. The U.S. Marshals implemented the Fugitive Safe Surrender (FSS) Program in an effort to bring in serious, high-level fugitives. However, it became clear after initial implementation that this national program drew more people with low-level offenses than the target audience, ultimately shifting the program's focus to low-level fugitives, leading to the U.S. Marshals discontinuing the program.

\section{Financial Burden}


For many jurisdictions, bench warrants are used as a tool not only to compel defendants to come to court, but also to pay fines, fees, and surcharges. In the 1983 Supreme Court case of Bearden v. Georgia, it was held that even if, "a State determines a fine or restitution to be the appropriate and adequate penalty for the crime, it may not thereafter imprison a person solely because he lacked the resources to pay it." However, too many municipal judges fail to ask whether a person has the means (Bannon, Nagrecha, \& Diller, 2010) and these fees can be disastrous for individuals and their families (Tabarrok, 2012). For people with limited resources, the percentage of their income going towards criminal justice costs can be exorbitant and disproportionate to their other living costs (Harris, Evans \& Beckett, 2010).

The warrant system has gotten swept up in the administrative role of assessing and collecting fees associated with crimes and the criminal justice system. This administrative purpose has shifted from the original intent of a warrant, which was to protect citizens against unreasonable search and seizure. The United States Department of Justice (2015) recognized this issue and in their scathing report on Ferguson, Missouri's criminal justice practices, it was found that, "[M]ost strikingly, the court issues municipal arrest warrants not on the basis of public safety needs, but rather as a routine response to missed court appearances and required fine payments" (p. 3). This investigation exposed the practice of bench warrants being used as a tool not to compel people to come to court - but rather, to subsidize the criminal justice system through the payment of fines, fees and surcharges.

In Malcolm Feeley's, seminal work, The Process is the Punishment (1979), his analysis of New Haven's lower criminal court suggests that the costs to participate in the formal court process are expensive and more of a hardship than individuals simply waiving their rights. This seminal work posits that the roles, institutions and their processes contribute to this problem, and that it is not solely the individual's fault. Feeley proposed that missing court is a "rational and reasonable" response due to the strain that the system causes people (1979, p. 240). The practices in Ferguson and across the country have contributed to the conception of low-level fugitive. With no means to pay these increasing criminal justice costs, bench warrants are issued, effectively incarcerating individuals for failure to pay.

\section{Low-Level Fugitive}

The DOJ investigation into Ferguson led to an increase in media attention on individuals living with a warrant. Articles appeared in the New York Times, The Washington Post, and National Public Radio describing nearly identical stories. Most 
stories began with an individual, often poor, receiving a ticket for a traffic violation. The individual lacks the money or resources to handle the ticket, resulting in unpaid fees, which quickly escalates into warrant issuance, subsequent arrest and days spent in jail. The arrest leads to job loss, children in need of a caregiver, and loss of public benefits. Then the individual is released on a new payment plan only to have additional fees assessed. This results in a period of living on the fringes trying to pay off the fees, but failing, only to be found again and re-arrested for failure to pay (e.g. Aspinwall, 2017; Benns, \& Strode, 2016; Holland \& Zhang, 2018; Robles \& Dewan, 2015; Schmadeke, 2017; Shapiro, 2015).

Flannery's (2013) work examining FSS revealed that failure to appear and failure to pay were the most common reasons for warrants. Further, Flannery and Kretschmar (2012), proposed that there is a group of inadvertent fugitives, those who unintentionally miss court. Through surveying FSS participants, it was discovered that warrants were stressful and impacted lives in a multitude of ways, from employment opportunities to childcare to driving (Galanek et al., 2016). Goffman's (2014) ethnographic study of Philadelphia fugitives revealed similar findings, as individuals described familial and romantic relationships, employment opportunities, and fear as areas affected by fugitive status. However, the FSS participants turned themselves in, and may be different than those who do not, and survey methods limit the amount of depth and context to understanding the problem. Goffman's work centered on seven central male informants, nearly all of whom could be described as violent offenders. Goffman posited that for these individuals, constant entanglement with the criminal justice system is normal and thus lives are built around avoiding the system. However, Goffman focused on chronic, violent offenders, not low-level offenders.

\section{The Current Study}

The limited research indicates that warrants impact employment, education, mental health, and relationships (Galanek et al., 2016; Goffman, 2009). There seems to be this low-level fugitive status that exists and impacts lives in a multitude of ways, but researchers have yet to establish the mechanisms by which people respond to this status. Previous research has focused on the amount and types of warrants (i.e., Bierie, 2014; Flannery, 2013; Flannery \& Kretschmar, 2012), survey data on the impact of warrants (i.e., Galanek et. al, 2016), and serious offenders (i.e., Goffman, 2009; 2014). However, no known studies have developed theory to identify the underlying constructs key to responding to this status. 
The purpose of this study is to understand how and why individuals fail to resolve their warrant status and their subsequent response to this status. The research question guiding this study is: How do individuals manage living with low-level fugitive status? The current study uses a grounded theory approach to explain and describe how individuals manage low-level fugitive status. This allows for the development of a theoretical foundation for this population that has been largely ignored in the scholarly literature. Understanding the key constructs relevant to this status has important practical implications for bench warrant prevention and intervention.

The current study addresses the critical gaps in understanding the experiences of individuals living with warrants for non-violent crimes. Information gathered from this hard to reach population will contribute to the general understanding of what it means to be a fugitive. The development of a conceptual map of the range of concerns experienced by this population has implications for intervention at the policy, system, local, and individual levels.

\section{Procedure}

This study was conducted in a mid-sized county in the Northeast United States. Nearly half of the 8,000 active warrants in this jurisdiction were categorized as bench warrants (personal communication, July 7, 2017). Interviews were conducted with two groups of respondents. The first group, warrant respondents, had a current or previous bench warrant for an original non-violent offense. The second group of respondents, trusted individuals, had a close relationship with someone that had a warrant.

Warrant individuals were recruited through local agencies, the Office of the Public Defender, and snowball sampling. The recruitment agencies provided services such as case management. The recruitment agency staff were provided with a study information sheet that was shared in-person or mailed to potential participants. Alternatively, at the end of each interview, respondents were asked to identify potential participants. These individuals were contacted by the first author via phone and screened for eligibility. Each of these respondents were asked to identify a person close to them who knew of their warrant status and these trusted individuals were interviewed on one occasion to gather more data on living with a warrant. In some cases, there was no trusted person, and so recruitment occurred through the same agencies that recruited warrant respondents. All respondents were compensated with cash and all interviews occurred in person at a public library or at the recruitment agency. 
Data collection stopped after theoretical saturation was reached; that is, no new information relevant to the emerging theory could be gained from additional interviews. While it was not possible to establish the number of study participants prior to the beginning of the study (Glaser \& Strauss, 1967/2012), it was reasonable to estimate that between 20 to 30 individuals would be interviewed (Creswell, 2013; Evans, 2013). The study began with interviewing 10-12 warrant respondents and then increased to 15; trusted individuals began with ten interviews and increased to eleven, for a total of 26 study respondents.

\section{Data Collection}

Data were collected through semi-structured interviews. All interviews were conducted and audio-recorded by the first author. An interview guide was developed in line with grounded theory methods. This included open-ended questions designed to understand the central phenomenon. After demographic and background questions, each interview began with the question, "Could you describe how you got the warrant issued, from the beginning to the end?" For trusted individuals, each interview opened with, "Could you describe what it is like to have a person close to you living with a warrant?" Probes followed all questions to gain more depth. The emerging analysis from previous interviews was used in subsequent interviews to confirm, modify, and elaborate on the findings. Memos about the thoughts and reflections of the emerging theory were completed after each interview. The study protocol was approved by the human subjects review boards from both universities.

\section{Data Analysis}

The study was grounded in data from participants who have experienced the process. A Straussian grounded theory (GT) approach was followed with data collection, coding, and analysis happening simultaneously (Glaser \& Strauss, 1967/2012). Respondents were interviewed and the data were transcribed shortly after the interview. The purpose of a cyclic process was to approach the next warrant respondent's interview with directed questions about the emerging concepts. Data analysis was completed using the NVivo software suite.

The analytical process gave rise to a core category and additional categories for how individuals manage bench warrant status. The core category is a central concept in which all other categories are integrated (Strauss \& Corbin, 1990). Throughout the coding process, intervening conditions, interaction strategies, and consequences emerged in the analysis. Intervening conditions refer to respondent personal histories 
and social, political, and cultural context. Action strategies describe how individuals responded to the phenomenon and intervening conditions. The result was a paradigm model of the hypothesized relationships between the categories and their properties (Glaser \& Strauss, 1967/2012). This model is a visual representation of how these categories related to the core phenomenon.

\section{Rigor}

Three methods were used to establish credibility and trustworthiness. During open coding, the second author read and coded 15\% of the total interviews. A Cohen's kappa interrater reliability test was conducted on the categories that emerged, with a Kappa > .61 considered acceptable (Warner, 2013). While grounded theory methods typically do not use interrater reliability testing, this approach enhanced the trustworthiness of the coding. The second method was a thematic audit. The first author created a table with the emerging concepts and one illustrative quotation within each concept. This thematic table was reviewed by a colleague to confirm that the codes and categories were reasonable and sensible.

The third method was a member checking focus group with warrant participants. After the twelfth warrant respondent interview, a focus group with four individuals who had a current or previous bench warrant was conducted. The focus group questions were based on the emerging categories to saturate and gain more depth. This allowed for feedback from informants to confirm that the emerging concepts fit with the reality of living with a bench warrant (Lincoln \& Guba, 1985). This also allowed the respondents to judge the accuracy and credibility of the findings themselves (Creswell, 2013).

\section{Findings}

The interviews were conducted over four months from 2018-2019. Interviews lasted from 30-90 minutes and every participant that confirmed the interview date and time with the researcher showed up for the interview. It became clear early in the interviews that most of the respondents did not differentiate between an arrest and bench warrant. In some cases, the respondents did not even know what type of warrant(s) they had. In many instances, the interviewer was able to determine the warrant type based on a series of questions.

\section{Respondent Characteristics}

Table 1 presents demographic and background information on the 15 warrant respondents. Six of the warrant respondents had at least one active bench warrant at 
the time of the interview. The length of time that someone had a bench warrant ranged from 1 day to 25 years. There was also wide variation in the age that the warrant respondents first had a bench warrant issued: 13 to 47 years old. The original charges on the bench warrants were wide-ranging from violations to a few non-violent felonies. The most common original charges were: possession of marijuana, disorderly conduct, and assault. Table 2 presents demographic and background information on the trusted individual respondents. These respondents were predominantly female and slightly older than the warrant respondents.

[Tables 1 and 2 here]

\section{Credibility and Trustworthiness}

The Cohen's kappa for the interrater reliability testing was .65, which is acceptable; there was $96.19 \%$ agreement. Most of the disagreement was associated with different amounts of text coded by each researcher, but still under the same category. The thematic audit confirmed that the statements made sense in their respective categories. The focus group informants confirmed the emerging findings and provided additional insight into living with a bench warrant. These results indicated that the coding was reliable.

\section{Categories}

Living with a warrant follows a dynamic series of actions and consequences. Eight categories emerged from the data: risk calculation, arrest evasion, power creation, emotional distress, surrender planning, warrant resolution, escalation, and distrust in the criminal justice system. The working definitions are presented alongside the categories in Table 3. From the interviews and subsequent analysis, a theory of lowlevel fugitive status emerged. The proposed relationships between the categories are indicated in Figure 1. Risk calculation was at the core of the process, and was closely linked to arrest evasion, emotional distress, warrant resolution, and escalation. Intervening conditions included age, knowledge of the criminal justice system, and distrust of the criminal justice system. These categories are the key mechanisms by which individuals respond to low-level warrant status.

[Figure 1 and Table 3 here]

\section{Risk Calculation}


Risk calculation was the core category that permeated the interviews, with constant assessments of how certain actions would play out. Risk calculation often began with the decision to appear in court or miss court, and ended once the warrant was resolved. There was a group of respondents that unintentionally missed court and once they realized that they failed to appear, they immediately turned themselves in, as explained by Ayanna who received a letter notifying her of her bench warrant status:

I was upset, like oh my God I got a bench warrant, oh my God I'm going to go to jail. I kept thinking oh my God what are my kids going to think if their mommy is in jail, they're going to have to come down to the jail to see their mom. I don't want to have my kids come down to visit me downtown.

For those that immediately turned themselves in, the cost was too high to stay on the (inadvertent) run. There was a small group of individuals that intended to show up in court, but then failed to appear because of a transportation issue or another reason out of their control.

For individuals that intentionally missed court, most of them calculated the risk of appearance versus not appearing and determined that not showing up had greater rewards, which was mainly staying out of jail (in the near term). Risk was always calculated relative to the likelihood of getting caught. Two important components of risk calculation were probability and severity. Probability was related to how likely it was that the behavior would lead to arrest. Severity was associated with how harsh the consequence of the action would be; this was often related to the original charge. Respondents distinguished between lower level offenses (e.g. violations) that result in zero or less than two weeks in jail versus higher level offenses that result in longer jail stays. Ava describes her boyfriend's calculation:

Interviewer: So, it sounds like your ex, he intentionally didn't show up in court?

Ava: Yeah, like if he would come up dirty on the urine he would just not go . . Interviewer: Yeah.

Ava: So, he would avoid a dirty drug test and take a missed court date instead, you know what I mean.

Whether the individual had been sentenced or not was relevant to risk calculation. In some instances, the respondent assumed that he or she would be taken into custody to 
serve out the remainder of their sentence and so those individuals were often willing to go to further lengths, like jumping out of a window, to avoid arrest.

Respondents who were employed sometimes calculated that continuing to work was worth the risk of being captured. Malik explained that he had a bench warrant for a low-level offense and did not think that the police were looking for him, so he continued to work. Others explained that employment made them vulnerable to capture, and so, ceased working.

Risk was calculated at various levels, from who respondents could socialize with to whether they could go outside during daylight hours to driving. For example, Julian would check in with his family, but never disclosed to them where he was living so that when the police knocked on his mother's door, she told the truth when asserting that she was unaware of where Julian was. However, other respondents described isolating themselves from friends because they did not want to jeopardize them. For some respondents, entire states were deemed unsafe, but in specific cases it might be worth the risk to visit, as Emma explained:

Interviewer: . . Y You won’t go back to New Jersey until you pay that $\$ 500 \ldots$. ?

Emma: You know I might but I'd just decide.

Interviewer: Depending on if something went wrong?

Emma: If my mom were in the hospital I would go in a heartbeat, I would go yes. . .

It was uncommon that individuals would engage in criminal behavior to avoid arrest, as that was too risky. For example, no one disclosed stealing to support their life on the lam. Instead, as Kiara explained, "I knew like . . . I'm not going to be able to run forever, I don't even have the resources like that so eventually I'm going to get caught."

\section{Arrest Evasion}

Respondents' lives were guided by doing what was necessary to avoid arrest. Most behavior to evade arrest was strategic, in that respondents intentionally acted to avoid arrest based on calculated risk. As respondents identified strategies to evade arrest, there was a constant assessment of potential outcomes associated with the behavior. Key strategies were avoidance, social isolation, hypervigilance, unpredictability, and hiding in plain sight. 
Avoidance permeated the interviews, especially efforts to stay away from the police. For example, as explained by Taye, ". . . and there was some times literally jumping out of windows [to avoid police]." In addition to avoiding law enforcement, other systems were deemed unsafe and must be avoided. There was a repeated concern that agencies with system affiliations (e.g., medical, public safety, social services, and employment) would share warrant status or address information with law enforcement, leading to their arrest:

Interviewer: Okay. What about like are you going to the doctors ...

Julian: No I don't go to see any doctors right now because I fear making an appointment will appear on the computer system or something will appear there. . .. I have a lot of health issues, I have hypertension, I have diabetes, I've got a lot of stuff I need my medication for right now which I don't have because of the situation.

Interviewer: Okay, so you're avoiding even getting your medication? Julian: Yeah.

Mia described a similar situation with her partner who was hit by a car, but refused medical treatment due to fear of being arrested in the hospital on his bench warrant. Medical systems were avoided, as were some shelters, and even public assistance, as explained by Erica:

DHS is able to track warrants in their system and stuff like that so a lot of our guys will refuse DHS services and a lot of them won't tell us why. I mean people aren't really open to share that they have warrants and things like that because they are afraid somebody is going to turn them in.

Other forms of avoidance include staying away from particular neighborhoods with heavy police presence, avoiding certain people, and not going out during the day. As explained by Carrie, “So, you know, he didn't go out a lot so it wasn't just avoidance of like benefits, it was also avoidance of driving places. He used it the way you would use a limited driver's license [to drive to work and the kids]." Avoidance often began as soon as the warrant was issued and, for some people, diminished as time progressed. For others, the consequence of capture was worse than the burden of avoidance and they continued dodging throughout the duration of this status. 
Social isolation was frequently described. Respondents had to be aware of whom they were around so as to not bring attention to their circumstance, but many respondents described going further to isolate themselves from everybody, as described by Jason:

I won't go out at all, you stay in the house, you eat, and sleep, and then you get bored and it's like I've got to go somewhere and the minute you go somewhere someone is like oh you know the police were looking for you . . . and now you go home again, you run back home.

In some cases, respondents identified family members or partners as being safe, but almost anyone else was considered untrustworthy. Social isolation was intentional, but an unintentional consequence was that individuals withdrew from support and resources. For some, living in isolation was worth the consequence if it meant that they would not be arrested; but for others, living so detached from society was not worth avoiding capture.

Hypervigilance, another strategy, came out mostly when asked about the police. Respondents, like Nick, explained "It just sucks because now every time I see a cop I have to look over my shoulder, you know what I'm saying." Hypervigilance is about an enhanced sense of alertness and behavior that prevents assumed danger, which often led to emotional distress such as panic or anxiety in the respondents.

Cultivating unpredictability was another strategy to evade arrest. Respondents shared examples of moving from place to place, not working, and erratic family contact. Julian explained, “Well I do look over my shoulder all of the time. I can't go and see family, I need to stay away from friends, I need to stay away from the streets, I need to stay away from [a] steady place, I need to move around for now." Kiara also had this to say, "Yeah I would move to different spots so I wouldn't be somewhere too long, like a couple different places, stay a couple days and then move to the next place." Unpredictability seemed to be more vital in instances where individuals knew that the police were actively looking for them.

Finally, there were respondents that continued their life as it were before, but in an effort to appear unsuspicious. Hiding in plain sight was a way to avoid unwanted attention. Respondents would continue typical activities, such as driving, walking in the community, working, and receiving public assistance. These respondents remained connected to their communities, as explained by Kiara: 
Everybody, my family and friends knew I had the warrant, I would come and go as I pleased. I walked down the street, the cops would look at me but I wasn't out there like that, they didn't know me by face or name. . .

Avoidance of formal systems and hypervigilance were the most common strategies, while other strategies such as cultivating unpredictability or hiding in plain sight, were less common. Respondents ranged in how long these strategies would last, for some they would come out of hiding briefly, often to find that the police were looking for them, resulting in a return to isolation.

\section{Power Creation}

Respondents felt powerless and some refused to go down without a fight. They repeatedly viewed the court system as being against them. Creating power to take control was echoed in the sentiment of, "Catch me if you can." As explained by Kiara:

My family couldn't believe it, you're not scared, no I'm not. It's actually fun and I want to see if they can recognize who I am if I had the warrant or not, and so it's basically catch me if you can.

Some respondents asserted that officers need to earn their paycheck. Brandon created power by running from the police, "I was running because I'm basically going to jail for nothing, in my eyes I'm going to jail for nothing, smoking weed, they're about to take my life away." James explained that these individuals frequently have such limited power that they take any advantage they can get. Sometimes the risk of getting caught was worth it, if it meant that they had exerted some power.

\section{Emotional Distress}

Respondents described intense negative emotions related to their warrant. While living with a warrant, participants described anxiety, depression, fear, sadness, and even embarrassment. This negative psychological state seemed to be chronic, affecting health and mental well-being. These unpleasant feelings, in turn, often caused more problems.

Carrie: He definitely has depression, he definitely has sleep problems, he uses a sleep apnea type of thing

Interviewer: Oh yeah, yeah. Do you think that's related to this? 
Carrie: I think it's related to depression and I think depression is related to constant stress and you know just he doesn't see a way forward to be the person he wants to be in his mind, like there's no way to get from here to there because of things that are out of his control.

Exhaustion was a key component of emotional distress and often coincided with surrendering or "giving up." Kiara explained, "I just came to a point where I was just being tired of running from house to house." Taye affirms this exhaustion leading to his arrest.

Taye: Every time they came there I was there, they just didn't know I was there that's how quiet I was. The time that they came looking for me my door was actually unlocked and they opened it and I was sleeping, I was just laying in my bed asleep, just like tired.

Interviewer: And that's when they got you.

Taye: That's when they got me, I was just tired.

Interviewer: What do you mean you were tired?

Taye: Just tired of everything that was going on, just everything. That's when I was picked up on the bench warrant and I said I just want to do my time and get it over with. I'm going to be free.

Emotional distress, such as fear, often motivated individuals to act in a certain way that escalated the situation. As explained by Taye, "I was in that room, I was like just like very isolated, very depressed, just like very depressed because it was like the most drama end of the year." The continuous threat of arrest weighed on people. Emma explained, "It's a terrible thing to have to hold over your head all the time, to want to take someone and show them where you lived and have to worry about the police coming."

\section{Surrender Planning}

Respondents expected that they would eventually be caught, and most respondents said that they would surrender at some point. Surrender plans ranged from contemplating the idea of turning themselves in, like Kiara describing that at every holiday she would consider turning herself in (but never did) to active surrender planning as explained by Emma, "He’s going to turn himself in in January," after he got 
his finances and housing in order. For some, there was a need for stability before turning themselves in, as explained by Erica:

So most of the time when people are deciding to surrender it's very much about their situation, so if they got an apartment coming up in two days they're waiting until they get their apartment and you know then they have the sense of being settled, they know they're coming out of jail, you're coming to your apartment, you have these supports as opposed to these people who know they're coming out of jail and coming back to the streets or back to the shelter.

Kiara's family also motivated her, "It [an amnesty program] was on the news and my grandmother seen the news and she called me and she was like . . . well she's [the judge] doing this thing: turn yourself in and she won't lock you up." While others, like Ayanna, described internal motivation to surrender, "I just came downtown at this point and [said] lock me up, I'm tired of running."

For some, surrender planning entailed getting money and resources together for their significant other, for others it was about saying their good-byes, and for still others, there was minimal planning. Surrender planning could occur even while evading arrest. For some, it was a concern about the future beyond their warrant, as explained by Mia:

So eventually he turned himself in, he finally turned himself in. I think he got so fed up with the running and he had come to a point in his life where he was actually looking for a job and wanting to make that change in his life and obviously he couldn't because if I do get this job and I have this one they're going to pick me up at work, and so finally he turned himself in and I remember it like it was yesterday.

\section{Warrant Resolution}

Bench warrants were resolved through either turning themselves in or being arrested by law enforcement. For those who surrendered, it was most common to show up at the courthouse and ask to be added onto the docket. A few respondents called their attorney and some turned themselves into the police station, as described by Jayden:

I'm sitting on the bench and my mom was starting to cry now and I was like oh man what did I do . . so they come get me and when they put me in handcuffs she was just like I can't watch you, just leave, I'm good, just go ahead. 
There were many respondents that surrendered as soon as they realized that they missed court or received notification that they had a bench warrant issued. Most of these respondents unintentionally missed court. On the other end were individuals who intentionally missed court and were "on the run," but were now ready to surrender. Some of these respondents described initial plans to never surrender, but then over time they became exhausted, and turned themselves in. It was more common for respondents who intentionally failed to appear to miss a compliance hearing because they had not followed through with their sentence. For these individuals, there was more risk associated with surrendering as they would likely be resentenced and incarcerated for more than 30 days.

\section{Escalation}

Bench warrants often resulted in increased sanctions or negative consequences for respondents. In a few cases the respondent's behavior escalated but, more frequently, escalation was the system's response to behavior. In this study, escalation was interpreted as a crossover category, one that both described individual behavior but also how the criminal justice system responded to behavior such as arrest evasion and surrender. Jayden explained how his bench warrant escalated things for him:

I showed up to the first [court appearance] when I came to court and I went to jail I had to go to court, then I came to the next one, the third one I missed, the third one was going to be dismiss the whole case because that was disorderly conduct, a slap on the wrist and I prolonged that case because of missing court. So then I had to go through the program, I had to go to do an anger management program just to get the case cleared up. I had to do all these things just because I missed court, if I wouldn't have missed court I wouldn't have had to do all those steps.

In this case, the system responded by escalating his sanctions. The escalation of individual behavior was seen in areas such as employment. Respondents that had calculated the risk was too high to work stayed away from employment and so had no resources to provide for their basic needs. Marcus shared about a young person that had a warrant and stopped showing up to work, "so he ended up losing his job for no call, you know . . . so then he lost his job but then he wasn't even around to know that he lost his job."

Respondents described other ways that things got worse for them. Some respondents reported that once arrested on the warrant, they would agree to plea deals to simply to get out of jail. When asked about fines and fees owed, many respondents had no idea 
how much money they had paid, while others responded "thousands of dollars" and still others responded they paid nothing because the amounts were converted to civil judgments. The interviews revealed that converting fines and fees to civil judgments was routine practice in this community. Once converted to civil judgments, these fines were no longer a criminal matter, effectively closing the case, but escalating economic problems for defendants.

Frequently, respondents described original non-criminal offenses escalating into criminal offenses for missing court. These included traffic infractions and city code violations that individuals cannot be jailed for. Yet, Jason was charged with an open container offense, but because of his failure to appear, he spent seven days in jail after being taken into custody.

\section{Intervening Conditions}

Many of the respondents raised concerns with the current justice system, and identified it as being unfair and untrustworthy. While distrust of the system was not identified as a strategy or a consequence, it did facilitate certain interaction strategies. Respondents described a system that did not respect, empathize, or show concern for their situation. Respondents identified differences in treatment based on the jurisdiction of the offense and the specific judge. Town and village courts seemed to issue bench warrants and process cases with wide variation which contributed to this distrust. Marcus explained that the system is unfair to black males in particular:

But I think our young people they get hassled for chillin' so some might say chillin', some might say loitering, just for being, right? but you figure if you're a young Black male especially and you're just hanging there, chillin' with the boys, coming out of the corner store, cops roll around the block, run everyone's ID like literally almost every day, every day anywhere you are you could be a potential of either getting arrested for the first offense, right, and that might be how it works, you're on the street they run everybody else, you got to go to jail, you go to court right, you don't go to court, now they issue a warrant and now again you're in this constant cycle that next time anything happens you're out walking around the neighborhood, anything happens at school, any time your name gets run you got a potential to go to jail.

The distrust was associated with judges, police and even laws in general. One respondent explained that he should not be facing such serious consequences for 
marijuana, while other respondents asserted that the judges did not allow them to explain their actions.

\section{Discussion}

This was a first step in exploring the process of living with a low-level warrant. Similar to what Damocles realized in the 4th century B.C., the respondents described the toll that living under a constant threat took on their daily lives. Risk calculation was integral to managing low-level fugitive status, with respondents constantly assessing how safe and unsafe people, places, and activities were. The ultimate goal, for those that were intentionally on the run, was to stay out of jail. Respondents with warrants issued post-adjudication often had more severe consequences (e.g. long-term detention) associated with warrant clearing, and so were apt to engage in more serious strategies to evade arrest.

A key strategy to evade arrest was social isolation, which often resulted in disconnection from resources and service providers. Some respondents refused public assistance and employment because of their status, making things worse for them. Respondents with offenses that would likely not result in a jail sentence still led their lives "on the run" due to bench warrants. As indicated in Figure 1, arrest evasion was closely associated with risk calculation, escalation, and emotional distress.

For some, the negative impact of the warrant resulted in self-initiated warrant resolution. For others, they would remain on the run, even exerting power by doing things like baiting the police to chase after them. All respondents described emotional distress, including anxiety and exhaustion. In the end, warrants were resolved through either turning themselves in or the police clearing the warrant. Inevitably, they would be incarcerated for some period of time. Families were impacted in similar ways, even asserting that it felt like they had a warrant themselves.

Risk calculation was intertwined with escalation, as behavior aimed at reducing the likelihood of arrest often resulted in increased negative consequences in most aspects of lives, such as emotional distress, employment loss, and disconnection from vital resources. The system's response to this behavior often included increased sanctions. As Sekhon (2017) explains, "warrants pose unique dangers, constitutional and otherwise . . outstanding warrants beget arrests and arrests beget more warrants" ( $p$. $1)$. 
Gouldin (2018) found that while there is a high number of bench warrants on any given day, the actual failure to appear rate is relatively low. Corey and Lo (2019) claim that FTA rates are similar to missed doctor's appointment rates and that most of the population that misses court does so inadvertently. Yet, in the current study, missing a court appearance resulted in a flood of negative consequences. Many respondents simply forgot their court date and then immediately surrendered. However, nearly every respondent that surrendered spent at least one night in jail, and most spent even more days incarcerated as a direct result of the bench warrant. This detention occurred in spite of original offenses that could not legally result in a punishment of jail. Even more troubling, local practice indicated that most of these offenses would not result in jail time. If this is the case, then is detention a reasonable response to missed court appearances?

Many respondents described distrust of the criminal justice system. This is unsurprising, as elements of structural disadvantage were identified in the interviews. For example, respondents described a burdensome, confusing court process (e.g., unclear on warrant type). Other respondents, such as Marcus, described living in communities with a heavy police presence, while still others described differences in warrant issuance dependent on jurisdiction. This finding is consistent with Feeley's work highlighting the importance of organizational features in encouraging failure to appear. He concluded that organizational features such as how well defendants understand court processes and what they believe the consequences of nonappearing to be, play the largest role in missed court appearances.

States are increasingly motivated by financial crises and so have begun to experiment with the decriminalization of various crimes, such as marijuana possession, driving on a suspended license, and traffic offenses (Natapoff, 2016). Natapoff asserts that without full legalization of certain "offenses," decriminalization still carries the punitive consequences and collateral impact on individuals. The current study's findings support this assertion, as individuals with "nonjailable" offenses and violations spent time in jail, often for longer periods than they could legally be sentenced for the original offenses.

This study provided support for Flannery and Kretschmar's (2012), proposition that there are important differences between intentional versus unintentional failure to appear. Most inadvertent fugitives immediately surrendered. However, some that unintentionally failed to appear became fearful of the bench warrant and had a lack of information about the potential consequences of their charges, which drove them to 
stay on the run. Those that intentionally stayed on the run determined that it was more important to be out of custody than in custody. Policies targeting interventions for these different groups should be adapted.

The FSS data indicated that $60 \%$ of the participants did not surrender previously due to financial limitations (Flannery \& Kretschmar, 2012), yet that theme did not emerge in the interviews. Instead, respondents were fearful of going to jail. Sampling and recruitment may partially explain this difference, with many study participants distrustful of the criminal justice system, and so would not participate in FSS. This difference may also be related to the local process of converting fines and fees to civil judgments, diminishing the reason for failure to appear being associated with inability to pay. While study after study confirms disproportionate arrest rates of people living in poverty (Looney \& Turner, 2018; Miller, 2015), in this study's jurisdiction, rather than wait for defendants to fail to pay, the judges almost immediately convert fines and fees to civil judgements. This practice, however, has social justice implications, such as the lack of ability to pay hearings.

\section{Limitations}

While the present study contributes to the bench warrant and fugitive literature, there are several limitations. It became clear by the third interview that while efforts were made to ensure that respondents had an active or previous bench warrant, in some cases, the warrant might have been an arrest warrant. However, this provides key information about the impact of bench warrants: warrant type might not matter when it comes to managing the status. Respondents were asked to recall their behavior years ago, and memories are not always reliable. The respondents may have poor recall; give desirable responses, or both. Efforts to reduce this bias included prompts such as, "Where were you living at the time?" in an effort to orient the respondents. Recruitment through the public defender's office can result in a biased sample. This threat was minimized by also recruiting from participants and other agencies.

Differences across jurisdictions, such as how unpaid traffic fines and fees are handled, local judicial authority and warrant clearing efforts may limit the transferability of these findings. The jurisdiction under study issued one bench warrant per incident; it is unclear if these results would be different for jurisdictions that issue one warrant per charge.

\section{Implications}


Goldkamp (2012) urged that next steps in this area should focus on understanding the nature of fugitive status and explanations for this fugitivity. This is the first study known to the authors that identified a set of concepts, definitions, and propositions that describe managing low-level fugitive status. This contribution to the field provides the framework for future studies to test these propositions and operationalize these concepts. A qualitative approach could examine the relationships between the concepts (e.g., emotional distress and escalation), and similar processes could be reviewed for potential explanations of the concepts and relationships. Gonzales' (2011) scholarship examining how undocumented individuals manage their status, may be fruitful in identifying convergence and divergence in theory development.

A closer examination of escalation and its role in the theory of low-level fugitivity is needed. Some respondents escalated behavior in ways such as isolating themselves, while others described a system response that increased sanctions. A quantitative study could examine the relationship between bench warrants and certain criminal justice outcomes (e.g., pretrial incarceration, plea bargain, conviction). For example, do cases with more bench warrants result in a higher percent of convictions? Or, incorporating data from other systems (e.g., homelessness and substance use), like the Homeless Management Information System, to study other ways that bench warrants escalate issues for individuals (i.e., losing housing). Future studies could examine some of the proposed group differences within the categories.

Pretrial detention increases the chance of pleading guilty in lieu of going to trial (Rempel, Kerodal, Spadafore \& Mai, 2017). A guilty plea has long-term effects, such as being part of a criminal record and the subsequent sentence associated with the guilty plea. In most jurisdictions, previous failure to appear (FTA) is a key indicator in the assessment for pretrial release, and so FTAs can have a significant impact on pretrial detention decisions and future criminal case outcomes (e.g., New York City Criminal Justice Agency, 2020). The lack of polices to de-escalate provides a window of opportunity. While some cities across the United States have implemented one-off amnesty programs, actual policy change to address the issue is lacking. However, one promising NYC practice is the implementation of a text-based court reminder system (Cooke et al., 2018). Another practice is with New York State Bail Reform, which requires putting an attorney on notice and 48 hours after the missed court data before a Judge to issue a bench warrant.

\section{Conclusion}


The current study presents an empirical foundation for understanding how individuals manage low-level fugitive status. The findings reveal not only the mechanisms by which individuals respond to this status, but that there are structural features in place that contribute to the fugitive problem. Participants described avoiding doctors, social isolation, and anxiety while living with warrants. They also described an unfair court system, even whilst admitting to committing the original crime(s). The majority of bench warrants are for minor offenses, yet this fugitive status significantly affects lives, regardless of the severity of the charges. This study provided a window into the lives of individuals with warrants, indicating that warrants impact lives in serious, longlasting ways.

Table 1. Warrant Respondent Demographic Data

\begin{tabular}{|c|c|}
\hline & Warrant Respondents $(n=15)$ \\
\hline \multicolumn{2}{|l|}{ Age } \\
\hline Mean & 36.9 years old \\
\hline Range & 21-57 years old \\
\hline \multicolumn{2}{|l|}{ Gender } \\
\hline Male & $8(53.3 \%)$ \\
\hline Female & $7(46.6 \%)$ \\
\hline \multicolumn{2}{|l|}{ Race/Ethnicity } \\
\hline Black & $11(73.3 \%)$ \\
\hline Latino & $2(13.3 \%)$ \\
\hline White & $2(13.3 \%)$ \\
\hline \multicolumn{2}{|l|}{ Number of Current Bench Warrants } \\
\hline Mean & 0.64 \\
\hline Range & $0-3$ \\
\hline
\end{tabular}


Total Bench Warrants in Lifetime

$$
\begin{array}{r|l}
\text { Mean } & 5.13 \\
\hline \text { Range } & 1-20
\end{array}
$$

\begin{tabular}{|c|c|}
\hline & Trusted Individuals $(\mathrm{n}=11)$ \\
\hline \multicolumn{2}{|l|}{ Age } \\
\hline Mean & 38.1 years old \\
\hline Range & 20-50 years old \\
\hline \multicolumn{2}{|l|}{ Gender } \\
\hline Male & $3(27.3 \%)$ \\
\hline Female & $8(72.7 \%)$ \\
\hline \multicolumn{2}{|l|}{ Race/Ethnicity } \\
\hline Black & $1(9.1 \%)$ \\
\hline Latino & $2(18.2 \%)$ \\
\hline White & $8(72.7 \%)$ \\
\hline \multicolumn{2}{|l|}{ Relationship w/ Warrant Person } \\
\hline Partner & $5(45.5 \%)$ \\
\hline Client & $4(36.4 \%)$ \\
\hline Brother & $1(9.1 \%)$ \\
\hline Uncle & $1(9.1 \%)$ \\
\hline
\end{tabular}

Table 2. Trusted Individual Respondent Demographic Data

Table 3. Theoretical Categories 


\begin{tabular}{|c|c|}
\hline Category & Working Definition \\
\hline Risk Calculation & $\begin{array}{l}\text { Assessment of risks and rewards associated with } \\
\text { particular actions, people, and places }\end{array}$ \\
\hline Arrest Evasion & $\begin{array}{l}\text { Strategies utilized to avoid getting arrested for } \\
\text { the warrant }\end{array}$ \\
\hline Power Creation & Taking control of status to feel a sense of power \\
\hline Emotional Distress & $\begin{array}{l}\text { Intense negative emotions associated with } \\
\text { warrant status }\end{array}$ \\
\hline Surrender Planning & $\begin{array}{l}\text { Contemplating and/or preparation taken to turn } \\
\text { oneself in }\end{array}$ \\
\hline Warrant Resolution & $\begin{array}{l}\text { The actions surrounding the warrant being } \\
\text { cleared, either self-initiated or from an external } \\
\text { source (e.g., law enforcement) }\end{array}$ \\
\hline Escalation & Increasing sanctions and/or problems \\
\hline Distrust in CJ system & $\begin{array}{l}\text { The belief that the CJ system, and actors within } \\
\text { the CJ system, are unreliable and unfair }\end{array}$ \\
\hline
\end{tabular}

Figure 1. Relationships between Categories 


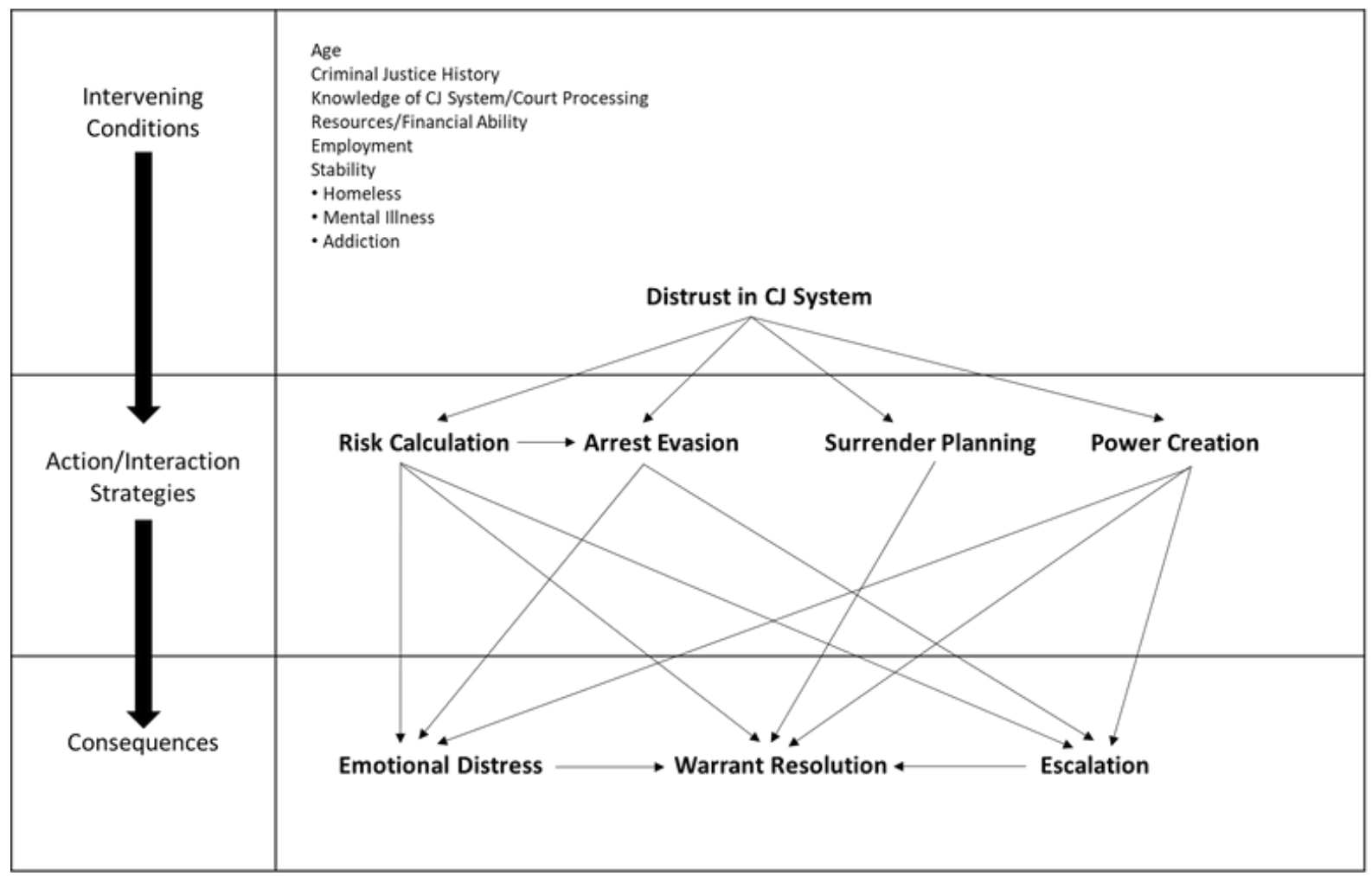

References

Aspinwall, C. (2017). Overlooked: As women go to jail in record numbers, who's watching out for their kids? No one. Dallas News. Retrieved from, https://interactives.dallasnews.com/2017/overlooked/

Bannon, A., Nagrecha, M., \& Diller, R. (2010). Criminal justice debt: A barrier to reentry. Brennan Center for Justice, New York University School of Law.

Bearden v. Georgia, 461 U.S. 660 (1983). Retrieved from, https://supreme.justia.com/cases/federal/us/461/660/

Benns, W. \& Strode, B. (2016). Debtor's prison in 21 st century America. The Atlantic. Retrieved from https://www.theatlantic.com/business/archive/2016/02/debtorsprison/462378/

Bierie, D. M. (2014). Fugitives in the United States. Journal of Criminal Justice, 42(4), 327-337.

Carleo-Evangelist, J. (2015). Parking ticket amnesty to begin Wednesday. Albany Times Union. Retrieved from https://www.timesunion.com/local/article/Albany_parking-ticketamnesty-to-begin-Wednesday-6520499.php 
Chauhan, P., \& Travis, J. (2018). Introduction to special issue: Misdemeanor Justice Project-A focus on criminal justice system responses to lower level offenses. Criminal Justice Policy Review, 29(6-7), 527-535.

Cicero, M.T. (trans. 1877). Tusculan disputations. Translated by C.D. Yonge. Project Gutenberg. Retrieved from https://www.gutenberg.org/files/14988/14988-h/14988$\underline{\text { h.htm }}$

Cooke, B., Diop, B. Z., Fishbane, A., Hayes, J., Ouss, A., \& Shah, A. (2018). Using behavioral science to improve criminal justice outcomes. University of Chicago Crime Lab and ideas42. Retrieved from https://urbanlabs.uchicago.edu/projects/using= behavioral-science-to-improve-criminal-justice-outcomes

Corey, E., \& Lo, P. (2019). The 'Failure to Appear' Fallacy. The Appeal. Retrieved from https://theappeal.org/the-failure-to-appear-fallacy/

Creswell, J. W. (2013). Qualitative inquiry \& research design: Choosing among five approaches ( $3^{\text {rd }}$ ed.). Thousand Oaks, CA: SAGE Publications.

Driscoll, B. (2015). Hundreds of New Yorkers line up for "Clean Slate" program to clear low-level warrants and summonses in Harlem. NY1. Retrieved from https://www.ny1.com/nyc/all-boroughs/news/2015/11/21/hundreds-of-new-yorkers-lineup-for--clean-slate--program-to-clear-low-level-warrants-and-summonses

Evans, G.L. (2013). A novice researcher's first walk through the maze of grounded theory: Rationalization for classical grounded theory. Grounded Theory Review: An International Journal, 1. Retrieved from http://groundedtheoryreview.com/2013/06/22/a-novice-researchers-first-walk-throughthe-maze-of-grounded-theory-rationalization-for-classical-grounded-theory 1

Federation of American Scientists. (2008). National Crime Information Center. Retrieved from https://fas.org/irp/agency/doj/fbi/is/ncic.htm

Feeley, M. (1979). The Process is the Punishment: Handling Cases in a Lower Criminal Court. New York: Russell Sage Foundation.

Flannery, D. J. (2013). Wanted on warrants. Kent, OH: The Kent State University Press. Flannery, D. J., \& Kretschmar, J. M. (2012). Fugitive Safe Surrender. Criminology \& Public Policy, 11(3), 437-459. 
Galanek, J., Duda-Banwar, J., Flannery, D.J., Kretschmar, J.K., Butcher, F. (2016). Fugitive Safe Surrender: A qualitative analysis of participants reasons for surrender and anticipated outcomes to inform program evaluation. Journal of Qualitative Criminal Justice and Criminology, 4(2), 161-187. Retrieved from http://www.jgcjc.org/archive.html

Glaser, B.G., \& Strauss, A.L. (2012). The discovery of grounded theory: Strategies for qualitative research, New Brunswick, USA: Aldine Transaction. Retrieved from http://ebookcentral.proquest.com/lib/rit/detail.action?docID=3410814. (Original work published 1967).

Goffman, A. (2009). On the run: Wanted men in a Philadelphia ghetto. American Sociological Review, 74(3), 339-357.

Goffman, A. (2014). On the Run: Fugitive Life in the Inner City. Chicago: The University of Chicago Press.

Goldkamp, J. S. (2012). Fugitive Safe Surrender. Criminology \& Public Policy, 11(3), 429-432.

Gonzales, R. G. (2011). Learning to be illegal: Undocumented youth and shifting legal contexts in the transition to adulthood. American Sociological Review, 76(4), 602-619.

Gouldin, L. P. (2018). Defining Flight Risk. University of Chicago Law Review, 85, 677742 .

Guynes, R. \& Wolff, R. (2004). Un-served warrants: An exploratory study. Washington, D.C. National Institute of Justice. Retrieved from http://www.ilj.org/publications/docs/Unserved_Arrest Warrants.pdf

Hager, G. (2005). Improved coordination and information could reduce the backlog of unserved warrants. Legislative Research Commission, Research Report No. 326. Retrieved from http://www.e-archives.ky.gov/Pubs/LRC/RR326.pdf

Harris, A., Evans, H., \& Beckett, K. (2010). Drawing blood from stones: Legal debt and social inequality in the contemporary United States. American Journal of Sociology, 115(6), 1753-1799.

Holland, G., \& Zhang, C. (2018). Huge increases in arrests of homeless in L.A. - but mostly for minor offenses. Los Angeles Times, Retrieved from http://www.latimes.com/local/politics/la-me-homeless-arrests-20180204-story.html 
Kinch, D. (2015). Municipal court launches amnesty program. AJC News. Retrieved from https://www.ajc.com/news/local/municipal-court-launches-amnesty_program/bKtee1UCpdbaHj $\underline{\text { IcKxNXBP/ }}$

Lincoln, Y.S., \& Guba, E.G. (1985). Naturalistic Inquiry. Newbury Park: Sage Publications.

Looney, A., \& Turner, N. (2018). Work and opportunity before and after incarceration. The Brookings Institution. Retrieved from https://www.brookings.edu/wpcontent/uploads/2018/03/es 20180314 looneyincarceration final.pdf

McKinley, J.C. (2017). 644,000 old warrants scrapped for crimes like public drinking. New York Times. Retrieved from https://www.nytimes.com/2017/08/09/nyregion/644000-old-warrants-scrapped-forcrimes-like-public-drinking.html

Miller, B.L. (2015). Social class and crime in The Encyclopedia of Crime \& Punishment. Retrieved from https://onlinelibrary.wiley.com/doi/abs/10.1002/9781118519639.wbecpx150

Natapoff, A. (2016). Criminal misdemeanor theory and practice. Oxford Handbooks Online. Retrieved from http://www.oxfordhandbooks.com/view/10.1093/oxfordhb/9780199935352.001.0001/oxf ordhb-9780199935352-e-9

New York City Criminal Justice Agency (2020). Release Assessment. Retrieved from https://www.nycja.org/release-assessment

Rempel, M, Kerodal, A., Spadafore, J., \& Mai, C. (2017). Jail in New York City: Evidencebased opportunities for reform. Center for Court Innovation, Vera Institute of Justice. Retrieved from https://www.courtinnovation.org/sites/default/files/documents/NYC Path Analysis Final \%20Report.pdf

Robles, F., \& Dewan, S. (2015). Skip child support. Go to jail. Repeat. The New York Times. Retrieved from https://www.nytimes.com/2015/04/20/us/skip-child-support-go-tojail-lose-job-repeat.html

Schmadeke, S. (2017). How a minor traffic offense in western Illinois ended in catastrophic brain damage in a Chicago jail. Chicago Tribune. Retrieved from 
http://www.chicagotribune.com/news/local/breaking/ct-met-chicago-police-warrantbrain-damage-20171128-story.html

Sekhon, N. (2017). Dangerous Warrants. Washington Law Review, 93, 967-1017.

Shapiro, J. (2015). Jail time for unpaid court fines and fees can create cycle of poverty. National Public Radio, Retrieved from https://www.npr.org/sections/codeswitch/2015/02/09/384968360/jail-time-for-unpaidcourt-fines-and-fees-can-create-cycle-of-poverty.

Strauss, A., \& Corbin, J. M. (1990). Basics of qualitative research: Grounded theory procedures and techniques. Sage Publications, Inc.

Tabarrok, A. (2012). Fugitives, outlaws, and the lessons of safe surrender. Criminology \& Public Policy, 11(3), 461-471.

United States Department of Justice, Civil Rights Division (2015). Investigation of the Ferguson Police Department. Retrieved from https://www.justice.gov/opa/pr/justicedepartment-announces-findings-two-civil-rights-investigations-ferguson-missouri

Warner, R. M. (2013). Applied statistics: from bivariate through multivariate techniques: from bivariate through multivariate techniques ( $2^{\text {nd }}$ ed.). Thousand Oaks, CA: SAGE Publications.

\section{Contributor Bios and Acknowledgements}

Janelle Duda-Banwar, $\mathrm{PhD} \underline{1}$

Assistant Research Professor, Center for Public Safety Initiatives

Department of Criminal Justice

Rochester Institute of Technology

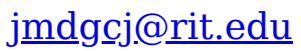

Jessica M. Burt, BS

Research Assistant, Center for Public Safety Initiatives

Department of Criminal Justice

Rochester Institute of Technology 


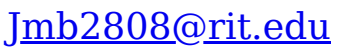

Janelle Duda-Banwar is an Assistant Research Professor in the Center for Public Safety Initiatives at RIT. Dr. Duda-Banwar earned her PhD in Social Welfare from Case Western Reserve University. Her research interests include courts, underserved communities and crime, policing, violence reduction, and applied research.

Jessica M. Burt was a Research Assistant in the Center for Public Safety Initiatives in the Department of Criminal Justice at Rochester Institute of Technology while this work was conducted. Her research interests include gun violence prevention, the intersection between public health and criminal justice, court processes, and corrections.

Funding and Acknowledgements

Funding for this study was provided by a grant from The Marie C. \& Joseph C. Wilson Foundation and additional support was provided by the Center for Public Safety Initiatives at Rochester Institute of Technology. The authors would like to acknowledge MC Collaborative, Save Our Youth, and the Monroe County Public Defender's Office for their generous involvement in the study.

Disclosure Statement

There is no financial interest or benefit to disclose by the authors.

\section{Footnotes}

1. Author Note: Study conducted while a Research Assistant at the Begun Center for Violence Prevention Research and Education at Case Western Reserve University and while at the Rochester Institute of Technology $\triangleq$ 